\title{
Increasing informativity of digital radiographic systems
}

\author{
O.D.Opolonin, V.D.Ryzhikov \\ Institute for Scintillation Materials, STC "Institute for Single Crystals", \\ National Academy of Sciences of Ukraine, \\ 60 Lenin Ave., 61001 Kharkiv, Ukraine
}

Received June 26, 2013

\begin{abstract}
In this paper questions of improving the information content of radiographic images is considered. Source of the new information is X-ray images of inspected object registered in several energy ranges. Three energy X-ray images of test objects with an effective atomic number from 7.08 to 8.07 were obtained. Using a photodiode-scintillator type detectors based on scintillator $\mathrm{ZnSe}(\mathrm{Te})$ the accuracy of substances separation by the effective atomic number $\sim 5 \%$ was achieved. We proposed a method for reconstructing the energy dependence of the mass attenuation coefficient.
\end{abstract}

Рассмотрены вопросы повышения информативности радиографических изображений за счет регистрации рентгеновского излучения, прошедшего через объект контроля, в двух, трех и более энергетических диапазонах. Получены трехэнергетические рентгеновские изображения тестовых объектов с әффективным атомным номером от 7.08 до 8.07. Достигнута точность разделения веществ по әффективному атомному номеру $5 \%$, при использовании детекторов типа сцинтиллятор-фотодиод на базе сцинтиллятоpa $\mathrm{ZnSe}(\mathrm{Te})$. Предложен метод реконструкции энергетической зависимости массового коэффициента ослабления.

Підвищення інформативності цифрових радіографічних систем. О.Д.Ополонін, В.Д.Рижиков.

Розглянуто питання підвищення інформативності радіографічних зображень за рахунок реєстрації рентгенівського випромінювання, що пройшло крізь об'єкт контролю, у двох, трьох і більше енергетичних діапазонах. Отримано триенергетичні рентгенівські зображення тестових об'єктів з ефективним атомним номером від 7.08 до 8.07. Досягнуто точність розділення речовин за ефективним атомним номером $5 \%$, при використанні детекторів типу сцинтилятор-фотодіод на базі сцинтилятора ZnSe(Te). Запропоновано метод реконструкції енергетичної залежності масового коефіцієнта ослаблення.

\section{Introduction}

Used in radiography X-ray sources have a wide range of braking radiation $[1,2]$. Registration of the radiation transmitted through a tested object using X-ray film have an integral character - in the sensitive emulsion of X-ray film the X-ray photons are absorbed in the wide energy range: from keV up to the boundary energy, which is determined by X-ray tube anode voltage $E_{0}=e \cdot U_{a}$, where $e-$ electron charge, $U_{a}-$ anode voltage. However, efficiency of detection of X-ray quanta by the film material has significant energy dependence - lowenergy is absorbed more efficiently than high-energy radiation.

The main information parameter in the traditional film radiography is the optical density (darkening) of developed film. Darkening of the film depends on the following factors: 1) spectrum and intensity of radiation incident on the inspected object - they determined by current and voltage of anode 
X-ray tube and anode material, thickness and material of a filter; 2) thickness, density and chemical composition of the inspected object; 3 ) energy dependence of the efficiency of detection of radiation by X-ray film, and 4) the exposure time and 5) film development conditions. Thus, the darkening of the X-ray film due to X-rays transmitted through the substance with a different effective atomic number $\left(Z_{\text {eff }}\right)$ may be identical (for the corresponding values of radiation thickness).

Separate registration of low-energy and high-energy parts of the broad X-ray spectrum give possibility to obtain the additional information about the object of radiographic control. The base of dual-energy radiography is significant difference of the energy dependence of the attenuation coefficient for substances with different atomic number. From the ratio of signals of a lowenergy detector (LED) and a high-energy detector (HED) can be estimated $Z_{\text {eff }}$ of the substance of the inspected object [4-8].

Thus, increasing the accuracy of the substances separation on the effective atomic number by obtaining radiographic images in three or more energy bands is the purpose of this work.

\section{Experimental}

For three-energy radiography experiment a prototype of three-energy scanner was developed (Fig. 1).

The prototype of three-energy scanner can realize several modes of scanning. Firstly, using variety of filters and energy selective properties of three detector arrays we can obtain three radiographic images in three different energy ranges at one time. Secondly, using precision mechanism for the object moving (Fig. 1., pos. 8) we can obtain three different images for three different anode voltages with different filters (for each of detectors arrays) and then combine these images with sufficient accuracy. The third mode: using a single detectors array separately three images at different anode voltages can be obtained and then these images with best accuracy can be combined.

The first mode of scanning is the most quick and easy. But it is a problem to achieve high energy selectivity with one anode voltage, using only filters. The solution can be found by using the multilayer X-ray filters (MXF) on Bragg diffraction principle. Such multilayer X-ray filter cuts from wide $\mathrm{X}$-ray spectrum the narrow band (with width $\pm 5 \%$ from peak energy of re-

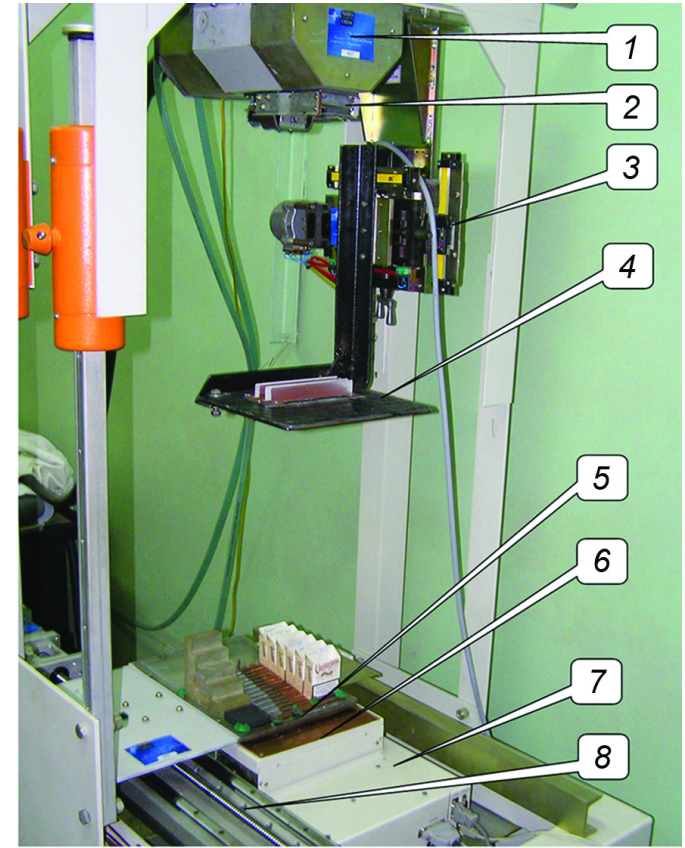

Fig. 1. Overview of three-energy scanner 1) X-ray source; 2) Preliminary collimator; 3) 2D positioning system; 4) Collimator for 3 fan beams; 5) Test objects on moving table; 6) three detector arrays; 7) Data acquisition electronics; 8) Moving mechanism.

flection) with the intensity of $50 \%$ of the initial intensity. Disadvantages of this mode are the necessity of accurate alignment of the relative position of three detector arrays and scattering of the detectors characteristics.

The second mode requires greater scan time and the alignment of three detector arrays. However, it provides much higher energy selectivity than the first mode.

The third mode is more time-consuming than the first two modes, but excludes the detectors alignment and scattering of the detectors characteristics.

Using the second and third scanning methods the shadow X-ray images of the test objects in three energy bands were obtained (Fig. 2).

Signals of detectors with low, medium and high energy denoted $L, M, H$, respectively.

The experiment was carried out in the framework of the grant NATO SfP-982823, the purpose of which was to increase probability of explosives detection. Therefore, the objects were "imitators" of the corresponding explosives in the chemical composition and effective atomic number: No.1 THT $Z_{\text {eff }}=7.08$; No.2 pyroxylin $Z_{\text {eff }}=7.34$; No.3 cyclonite $Z_{\text {eff }}=7.22$; No. 4 TEN $Z_{\text {eff }}=7.38$; No.5 Amatol $Z_{\text {eff }}=7.41$. 
Table. The effective atomic number of the test samples

\begin{tabular}{|c|c|c|c|c|c|c|c|c||}
\hline \hline Test samples & No.1 & No.2 & No.3 & No.4 & No.5 & No.6 & No.7 & No.8 \\
\hline$Z_{\text {eff }}$ & 7.08 & 7.34 & 7.22 & 7.38 & 7.41 & 8.07 & 7.51 & 7.12 \\
\hline
\end{tabular}

The principle of using two coordinate or two-dimensional (2D) identification palette (Fig. 2a) is the following. If we display on plane all points corresponding to the radiographic image at coordinates $(x, y)$, where $x$ object attenuation properties (e.g., $H$ or $(H+M+L) / 3), y$ - value characterizing the material (e.g., $H / M, H / L, M / L$ and other), then combining a set of points with a $2 \mathrm{D}$ color palette, we can assign to each point of radiographic image the corresponding color and brightness. The developed software has possibility to use as a palette any picture in bmp and jpg formats. Such a picture can be prepared using graphical editor with the dependences obtained experimentally.

The principle of using three coordinate or three-dimensional (3D) identification palette (Fig. 2b) is the following. Combining standard RGB color palette and Cartesian coordinate system, we obtain the $3 \mathrm{D}$ color palette. In the RGB palette the brightness of each color is the integer number from 0 to 255. Thus, for each point of the cube $256 \times 256 \times 256$ we can assign a color $(16,777,216$ colors $)$. If in 3D Cartesian coordinate system we display all the points corresponding to the radiographic image at coordinates $(x, y, z)$, where $x \sim$ object attenuation properties (e.g., $H$ or $(H+M+L) / 3)$, $y$ - value characterizing the dependence $\mu_{m}(E)$ in the one energy range, $z-$ value characterizing the dependence $\mu_{m}(E)$ in other energy range, then the color of a pixel of the radiographic image can be assigned according to the RGB identification palette.

If we use 3 identification palette it can be clearly seen (Fig. 2b) that corresponding to the different test samples points form some areas. The size of these areas are determined by instability of X-ray source, scattering of detector characteristics and by heterogeneity of the chemical composition of the test objects. Areas of the points corresponded to the used test objects are clearly distinguishable despite of the similar values of $Z_{\text {eff }}$.

Using $2 \mathrm{D}$ and $3 \mathrm{D}$ identification palettes, it is possible to distinguish the imitators of explosives (Fig. 2) even with small difference in their $Z_{\text {eff }}$ values (from 7.08 to 8.07) (Table).

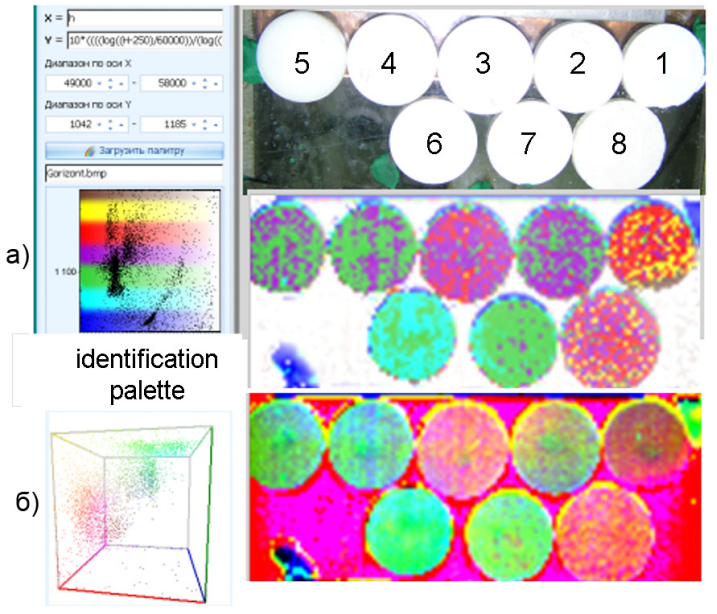

Fig. 2. Photo and three-energy images of imitators of explosives obtained with: a) 2D identification palette and b) 3D identification palette.

\section{Theory}

As a result of interaction of radiation with the substance, the $\mathrm{X}$-ray radiation intensity decreases [3, 9]:

$$
I(E)=I_{0}(E) \cdot e^{-\mu_{m}(E) \cdot \rho \cdot x},
$$

where $I_{0}(E)$ is the initial intensity of X-ray radiation (radiation energy flux density), $\mu_{m}(E)$ is the mass attenuation coefficient, and $x$ is the attenuating layer thickness.

Let us assume that we obtained three values of signal $(H, M, L)$ for each pixel of the image using three monochromatic radiation sources with energies $E_{1}, E_{2}, E_{3}$. Then these signals can be described in the following way:

$$
\begin{aligned}
& L=I_{0} \cdot e^{-\mu_{m}\left(E_{1}\right) \cdot \rho \cdot x,} \\
& M=I_{0} \cdot e^{-\mu_{m}\left(E_{2}\right) \cdot \rho \cdot x}, \\
& H=I_{0} \cdot e^{-\mu_{m}\left(E_{3}\right) \cdot \rho \cdot x},
\end{aligned}
$$

where the initial radiation intensity $I_{0}$ is similar for all three energies $E_{1}, E_{2}$ and $E_{3}$.

From expressions (2-4), for each pixel of a three-energy image three values of parameter $\mu_{m}\left(E_{1}\right) \cdot \rho \cdot x$ can be calculated:

$$
\mu_{m}\left(E_{1}\right) \cdot \rho \cdot x=-\ln \left(I_{0} / L\right),
$$




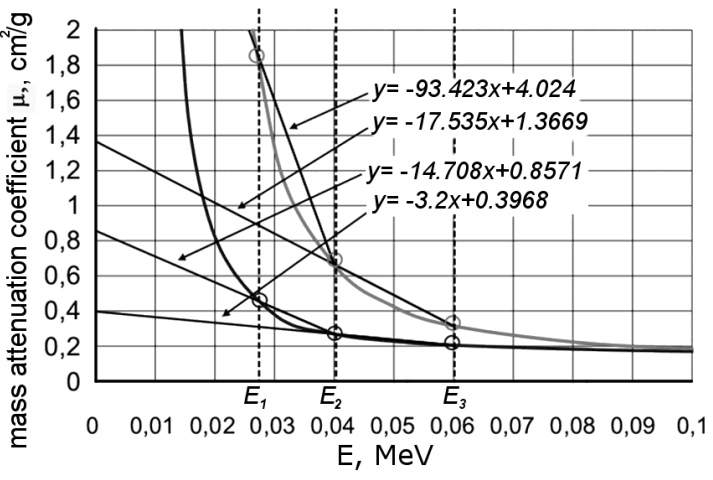

Fig. 3. Piecewise-linear approximation of mass attenuation coefficient $\mu_{m}(E)$ for two different substances in two energy ranges.

$$
\begin{aligned}
& \mu_{m}\left(E_{2}\right) \cdot \rho \cdot x=-\ln \left(I_{0} / M\right), \\
& \mu_{m}\left(E_{3}\right) \cdot \rho \cdot x=-\ln \left(I_{0} / H\right) .
\end{aligned}
$$

The left-hand side of expressions (5-7) contains the product of substance characteristics that are not a priori known thickness, density and mass attenuation coefficient. Using three energy ranges, one can obtain two independent relations for mass attenuation coefficient:

$$
\begin{gathered}
\mu_{H / M}=\frac{\mu_{m}\left(E_{3}\right)}{\mu_{m}\left(E_{2}\right)}=\frac{\ln \left(I_{0} / H\right)}{\ln \left(I_{0} / M\right)}, \\
\mu_{M / L}=\frac{\mu_{m}\left(E_{2}\right)}{\mu_{m}\left(E_{1}\right)}=\frac{\ln \left(I_{0} / M\right)}{\ln \left(I_{0} / L\right)} .
\end{gathered}
$$

Expressions (8) and (9) do not contain density and thickness of the inspected object, allowing piecewise-linear approximation of $\mu_{m}(E)$ for two energy ranges I) $E_{1} \div E_{2}$ and II) $E_{2} \div E_{3}$ (Fig. 3).

For the approximating linear dependence:

$$
\mu_{m}(E)=a \cdot E+b
$$

the constant $a$ determines the slope and is essentially dependent upon the substance material. The constant $b$ depends upon many factors and cannot be easily calculated from signals $(L, M, H)$ obtained in the experiment. However, at fixed values $E_{1}, E_{2}$ and $E_{3}$ the $\mu_{m}(E)$ dependence in this case can be approximated by two linear segments (Fig. 3).

It is obvious that further increase in the number of energy ranges will lead to higher reconstruction accuracy of the $\mu_{m}(E)$ dependence. Thus, the transition from two-energy to multi-energy (spectrometric) radiog-

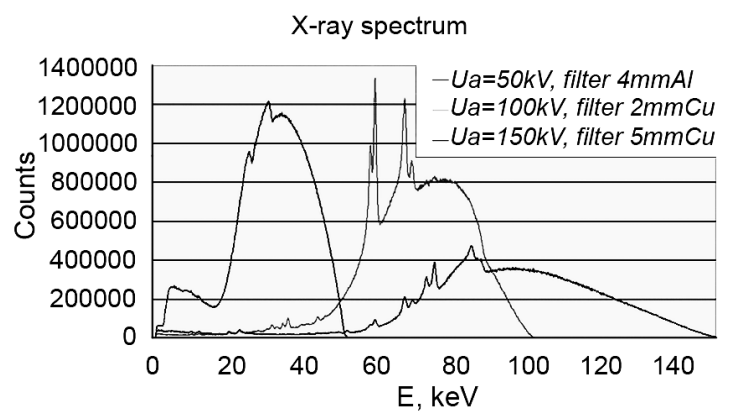

Fig. 4. X-ray tube emission spectra for different anode voltages and in different filtration conditions.

raphy opens substantially the new possibilities for increasing the informativity of radiographic and tomographic inspections.

Then, for energy range I) and II) (Fig. 3) we can write down the expressions (8) and (9) using (10) in following way:

$$
\begin{gathered}
\mu_{H / M}=\frac{\mu_{m}\left(E_{3}\right)}{\mu_{m}\left(E_{2}\right)}=\frac{\ln \left(I_{0} / H\right)}{\ln \left(I_{0} / M\right)}=\frac{a_{I I} \cdot E_{3}+b_{I I}}{a_{I I} \cdot E_{2}+b_{I I}}, \\
\mu_{M / L}=\frac{\mu_{m}\left(E_{2}\right)}{\mu_{m}\left(E_{1}\right)}=\frac{\ln \left(I_{0} / M\right)}{\ln \left(I_{0} / L\right)}=\frac{a_{I} \cdot E_{2}+b_{I}}{a_{I} \cdot E_{1}+b_{I}},
\end{gathered}
$$

whence we find:

$$
\begin{aligned}
& a_{I}=\frac{\left(\ln \left(I_{0} / M\right) / \ln \left(I_{0} / L\right)\right)-1}{E_{2}-E_{1} \cdot\left(\ln \left(I_{0} / M\right) / \ln \left(I_{0} / L\right)\right)} \cdot b_{I}, \\
& a_{I I}=\frac{\left(\ln \left(I_{0} / H\right) / \ln \left(I_{0} / M\right)\right)-1}{E_{3}-E_{2} \cdot\left(\ln \left(I_{0} / M\right) / \ln \left(I_{0} / L\right)\right)} \cdot b_{I I}
\end{aligned}
$$

Substantial variation of the $\mu_{m}(E)$ dependence is observed, with the majority of substances, in the energy range up to $100 \mathrm{keV}$ [3]. Thus, to carry out experiments on detection of differences among "light" substances (which include many explosives), the following anode voltages and filtration conditions were chosen (signals obtained in the experiment from three detector arrays can be designated as $H$ for high-energy detector, $M$ for medium-energy detector (MED) and $L$ for low-energy detectors, respectively:

$L-U_{a}=40 \mathrm{kV}, I_{a}=10.5 \mathrm{~mA}$, filter Al, thickness $2 \mathrm{~mm}$;

$M-U_{a}=60 \mathrm{kV}, I_{a}=13.4 \mathrm{~mA}$, filter - Al, thickness $12 \mathrm{~mm}$;

$H-U_{a}=90 \mathrm{kV}, I_{a}=14.9 \mathrm{~mA}$, filter - Cu, thickness $2 \mathrm{~mm}$.

Filtration was used for better separation of these three energy ranges. 


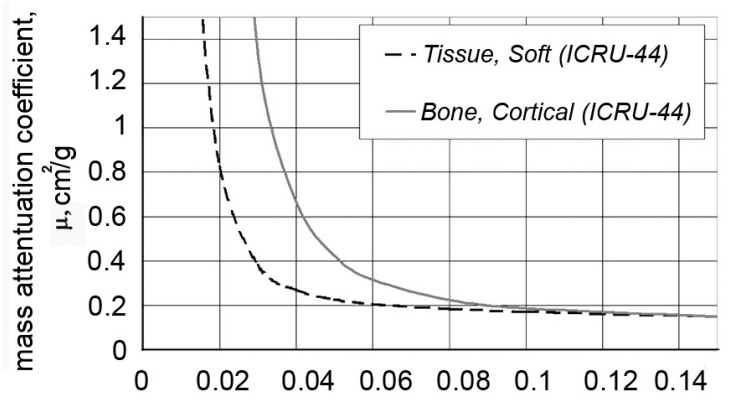

a)

E, MeV

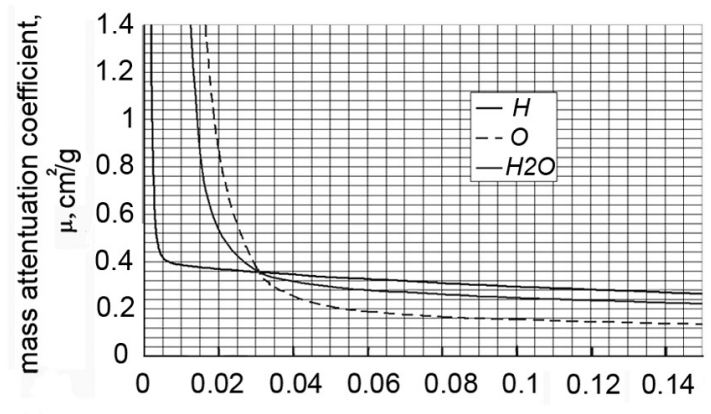

b)

$\mathrm{E}, \mathrm{MeV}$

Fig. 5. The energy dependences of the mass attenuation coefficients for the soft tissue and bone (a) hydrogen, oxygen and water (b).

For non-monochrome X-ray radiation, a notion of the effective radiation energy $E_{\text {eff }} \approx(2 / 3) \cdot E_{\text {max }}$, is used, where $E_{\text {max }}$ is the maximal possible $\mathrm{X}$-quantum energy determined by the anode voltage. Then, at $U_{a 1}=$ $40 \mathrm{kV}, U_{a 2}=60 \mathrm{kV}, U_{a 3}=90 \mathrm{kV}$, we find $E_{1}=27.7 \mathrm{keV} ; E_{2}=40 \mathrm{keV} ; E_{3}=60 \mathrm{keV}$.

Thus, using the signal values from three detector arrays $L, M, H$ and knowing the radiation energies $E_{1}, E_{2}, E_{3}$, we obtained the values of $a_{\mathrm{I}}$ and $a_{\mathrm{II}}$, which were used for construction of 2D and 3D identification palettes in the experiment described above.

\section{Discussion}

The main factors affecting the accuracy of substances separation by their effective atomic number are:

- emission spectrum of the X-ray tube, passing on the controlling object $I_{0}(E)$;

- difference in the radiation attenuation coefficient by the object material depending upon energy;

- energy selective properties of the detector.

As radiation source was used an X-ray source with a tungsten anode and maximum anode voltage $160 \mathrm{keV}$. By changing the anode voltage and using filters from aluminum and copper of various thicknesses we can obtain X-ray radiation in different spectral bands (Fig. 4).

Among objects of radiographic testing, depending on the DRS (digital radiography systems) application, the material of the object of control can vary greatly on radiation thickness, size, chemical composition, etc. The energy dependence of the attenuation coefficient for the test object $\mu(E)$ can be measured experimentally or calculated. The experimental dependences $\mu_{m}(E)$ are often used for objects having a complex chemical composition, such as biological objects (Fig. 5a).

For individual chemical elements of the periodic table according $\mu(E)$ were measured and are listed in the references [3]. For chemical compounds and mixtures dependence $\mu_{m}(E)$ can be calculated by the formula [3]:

$$
\begin{gathered}
\frac{\mu(E)}{\rho}= \\
=a_{1} \cdot\left(\frac{\mu(E)}{\rho}\right)_{1}+a_{2} \cdot\left(\frac{\mu(E)}{\rho}\right)_{2}+\ldots+a_{n} \cdot\left(\frac{\mu(E)}{\rho}\right)_{n},
\end{gathered}
$$

where $(\mu(E) / \rho)_{i}$ is the mass attenuation coefficient of the $i$-th element, which is part of the chemical compound, $a_{i}$ is weight fraction of the $i$-th element in compound. Calculated dependence $\mu_{m}(E)$ for water is shown in Fig. 5b.

Energy selective properties of detector (scintillator-photodiode type) are mainly determined by material and thickness of the scintillator. The efficiency of absorption of $\mathrm{X}$-ray radiation for various thicknesses of the scintillation crystal $\mathrm{ZnSe}(\mathrm{Te})$ is shown in Fig. 6.

The main source of information about material of the object is the energy dependence of the attenuation coefficient. Spectrometry of the initial radiation and spectrometry of the radiation penetrated through the test object give us possibility to reconstruct dependence of $\mu(E)$ with sufficient high accuracy. In practice, Dual Energy DRS for customs control usually use two detectors arrays - HD and LD, placed one behind the other. In LD used thin scintillator $(0.5 \div 0.7 \mathrm{~mm})$ with low $Z_{\text {eff }}$, in the HD used a scintillator with big $Z_{\text {eff }}$ and optimal thickness for the detection of highenergy part of the spectrum. Moreover, between HD and LD the copper filter of thickness $0.4 \div 0.6 \mathrm{~mm}$ is set. Thus, in the DRS 
for customs control is possible to obtain two radiographic images in two overlapping energy bands, which provides the rough separation of substances: $Z_{\text {eff }} \leq 10 ; 10<$ $Z_{\text {eff }} \leq 20 ; Z_{\text {eff }}>20$.

Using more than two energy ranges allows to increase significantly the information content of digital radiography and tomography systems. Drawing analogy between radiography and photography we can characterize the information content increase as follows. The main stages of the development of photography can be considered as a transition from black and white images to color images, and then the transition from film to digital technology. Color image contains much more information about spectral composition of optical radiation than black and white image, and digital technology greatly simplifies and speeds up the process of the image obtaining.

In radiography, the transition from film to digital technology has already received significant development, and proposed above the multi-energy approach can serve as a starting point for obtaining colored radiographic images. In this case, different parts of the image with different dependents $\mu_{m}(E)$ can be marked by different colors. Application of the proposed method for tomography allows to obtain more information about the internal elements of the test object. For example, in medicine it will be possible to determine not only density of the internal organs and structures, but also the hypothetical chemical composition: the type of gallstones in liver and kidneys; the composition of blood vessels plaques; the content of calcium in the bones; diagnosis of cancer, and so etc., and in security systems - improving the accuracy of identification of explosives.

\section{Conclusions}

As a result of our model calculations and experiments, the following conclusions could be made.

The obtained basic relations for three-energy reconstruction of the mass absorption coefficient vs. energy dependence can be also used in the multi-energy case. Threeenergy digital radiography ensures substantially higher informativity of radiographic images due to improved distinction between substances with close effective atomic numbers. In our experiments, distinctions were

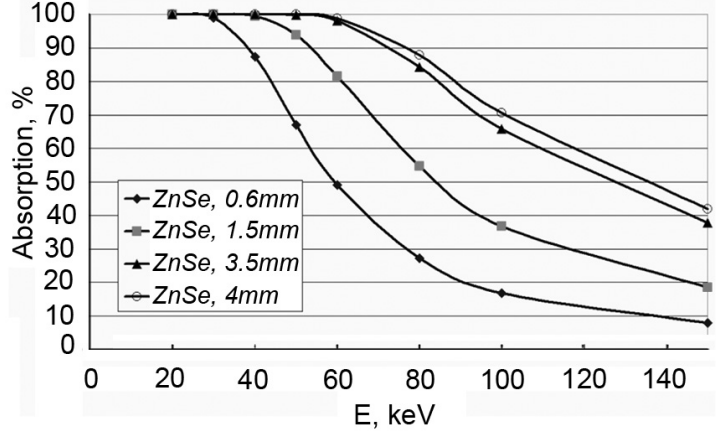

Fig. 6. Energy dependences for absorption by zinc selenide samples of different thickness.

clearly noted between "light" substances (in the $Z_{\text {eff }}$ range from 7.08 to 8.07 ) that differ in their $Z_{\text {eff }}$ values just by $5 \%$. The use of three and more energy ranges in the digital radiography and tomography opens possibility for creation of radiographic systems of the new generation for medicine, non-destructive testing and customs inspection.

Acknowledgements. This work was supported in part by NATO project SfP982823.

\section{References}

1. V.N.Vasiliev, L.A.Lebedev, V.P.Sidorin, R.V.Stavitsky, Energy Spectra of X-ray Machines, Handbook, Energoatomizdat, Moscow (1990) [in Russian].

2. Rentgenotechnika, Handbook, ed. by V.V.Klyuyev, 2nd ed., Rev. and Add, Mashinostroenie (1992), Moskow [in Russian].

3. O.F.Nemetz, Y.V.Gofman, Handbook of Nuclear Physics, Naukova Dumka, Kiev (1975) [in Russian].

4. V.Ryzhikov, S.Naidenov, Pis'ma v Zh.Tekhn. Fiz., 28, 71 (2002).

5. V.D.Ryzhikov, B.V.Grinyov, V.G.Volkov et al., Questions of defense equipment, ser. "Technical means to counteract of terrorism", Issue 7, 8 (2008), p.43.

6. V.Ryzhikov, O.Opolonin, O.Lisetska et al., Proc. of SPIE, 7805, 1 (2010).

7. V.Ryzhikov, O.Opolonin, S.Naidenov et al., Multi-Energy Radiography on the Basis of Scintillator-Photodiode Detectors. Symposium on Radiation Measurements and Application, May 21-23, 2002, The University of Michigan, Abstr., p.75.

8. V.D.Ryzhikov, O.D.Opolonin, D.N.Kozin et al., Visnik NTUU "Kuivsky politehnichny institut", seriya "Pruladobuduvannya", 29, 128 (2005).

9. F.H.Attix, Introduction to Radiological, Wiley-Interscience, New York (1986). 